\title{
DRAFT JIG STRUCTURE DESIGN FOR MEASURING DEFORMATION OF THIN-WALLED ROBOTIC OR CONVEYOR COMPONENTS
}

\author{
Peter Michalik', Jozef Zajac', Luboslav Straka' , Lukasz Nowakowski², Martin Ambrozy³ \\ 1 Technical University of Kosice, Faculty of Manufacturing Technologies with seat in Presov, Bayerova 1, 08001, \\ Slovakia, e-mail: peter.michalik@tuke.sk \\ 2 Kielce University of Technology, Katedra Technologii Mechanicznej i Metrologii, Kielce, Poland, e-mail: \\ lukasn@tu.kielce.pl \\ 3 Levoča, Francisciho 33, 082 71, Slovakia, e-mail: martin.ambrozy@gmail.com
}

Received: 2018.05.10

Accepted: 2018.06.15

Published: 2018.09.01

\begin{abstract}
The paper presents the general function, the division and the description of the main jig parts. It gives account of the basics and principles of a measuring jig structure using CAD applications. The main part delves into design of individual measurement jig options for measuring deformations of thin-walled robotic and conveyor components. Tension and stress analyses for each option have been performed. Subsequent to stress analysis, a suitable option was selected, with a description of its main parts, the production process and the necessary production equipment. Finally, the jig produced for the purpose of measuring deformation of thin-walled robotic and conveyor components is presented.
\end{abstract}

Keywords: thin walled, robotic, conveyor.

\section{INTRODUCTION}

At present, constant introduction of new products increases the requirements for production process accuracy and speed. The acceleration and greater precision of the production process makes it possible to make work more productive and to increase the productivity of businesses. Labor productivity is enhanced by improving production methods, tools, machine tools and other production equipment.

Labor productivity of production equipment is established by the number of products manufactured over a certain time. In addition to reduction in running time of major cycles, greatly influenced by machine and tool performance, even the time cycles of all secondary activities are constantly shortened, too. Particularly important is the reduction of time needed for secondary activities if the main cycle time is significantly shorter than the time required by the secondary activities.
This fact becomes even more pronounced with the emergence of new technologies, especially highspeed machining. One of the ways to shorten the time needed for secondary activities is jig deployment. In chip production of thin-walled components designed for robotic structures, it is necessary to monitor and eliminate the oscillation of cutting tools, which translates into reduced quality of their surface and thus their lifetime [1,2].

Currently, progressive technologies for thinwalled component production are gaining ground [3]. These include laser and waterjet machining [4].

Due to an ever-increasing range of products with simultaneous increase in small-batch and piece production, the importance of modular products increases, too. The use of modular elements significantly rationalizes the jig design and structure [5]. This advantage is further highlighted by the possibility of using electronic catalogs, allowing for the necessary jig element to be read by the CAD system directly $[6,7]$. Nowadays, the 
CAD systems provide a comprehensive solution to a new product development and design stage. They are based on either a 2D or a 3D component modeling module [8].

Thin-walled components are used as structural elements of frames, pillars, various beams, roller seats, as well as movable elements such as press rollers $[11,12]$ in the structure of trough and hose conveyors $[9,10]$.

Prior to jig assembly, CAD systems provide users with the option to run its geometric (ability to assemble the parts), kinematic (component insertion and removal) and, if necessary, numerical (strength, thermal and deformation calculations) simulation [13]. Modeling, analyses and testing of virtual jig models are becoming a part of the engineering activities led by CA systems.

Aslany et al. evaluated the behavior of SWT columns by the Finite Element Model (FEM), including the effects of initial local imperfections and residual degrees of stress, using the commercially-available ABAQUS software. In addition, they also ran a comparison with the prediction of axial load capacity using the proposed design model [14].

Fang et al. investigated and analyzed the load in a three-stage steel rim rolling, using the finite element method. They also developed the rolling process simulation for the ABAQUS software.

They studied the distribution of wall thickness and the equivalent plastic deformation on the edge formed on the wheel, from which it is possible to summarize the role of three cylindrical passages and rim formation characteristics. They analyzed the problems of cracking welds, developed a model of molding matrices with different inclination angles of shaping surfaces and described their impact on the formation of wheel rim results [15].

Johnsson et al. designed and analyzed the welded chassis beam from an optimized lightweight welded structure for the articulated conveyor. He used a new class system for highstrength steel welding. The requirements for static strength and fatigue were met both met in the new chassis beam design [16].

Using the finite element method, Troive et al. analyzed a structural element of a vehicle made of high strength steel types. The use of this type of material significantly reduces the structural weight due to its notable durability. He introduced a new design of the spring, which depends mainly on the material used, but also on the particular shape of the manufactured component. Changing the shape of the spring helped to achieve the reference geometry of the whole structure [17].

Murčinková et al. analyzed the stress distribution in single / multilayer areas applied to machining tools. She presents an analysis performed on single-layer, double-layer and multilayer coatings using numerical models to detect enhanced stress distribution and the most stressed zones in these 1-10-micron tombs. The paper describes the analysis of stress in thinner or superimposed layers of coatings up to structure breakage by comparing simulation methods and tracking of thin-walled robotic and conveying components produced in the process of rounded surface machining [18], [19]. When the finite element method is applied, it is also advisable to establish the degree of the risk of failure manifested as differences between the simulated and the executed process [20].

\section{ALTERNATIVE PROPOSAL}

One of the jig design tasks is to come up with a solution and a concept of three different alternatives, from which the most appropriate will be selected and subsequently manufactured to be used in measurements. From the technical point of view, elasticity and strength are of extreme importance. This is clear to anyone who notices different construction, engineering or other structures and technical equipment. Therefore, a designer must well understand structural materials. He must be well acquainted with their capabilities and properties, and he must be confident when it comes to their elasticity and strength. In addition, his intuition should guide him to the most suitable technical and design solutions. Flexibility and

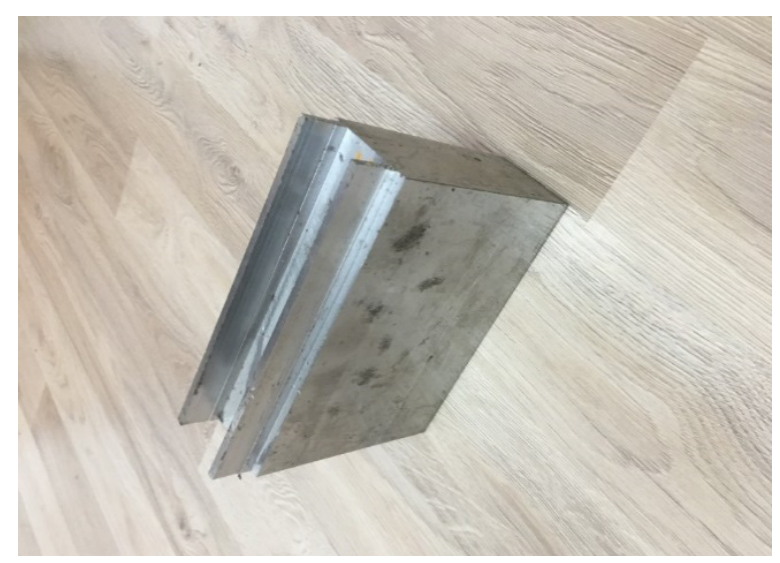

Fig. 1. Example of a thin-walled component for a robot or a conveyor 


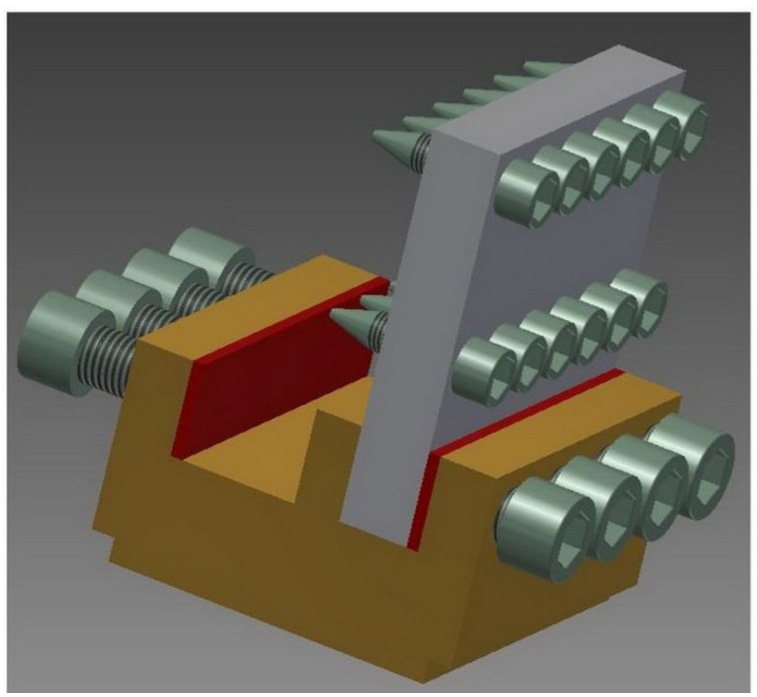

Fig. 2. First draft jig design alternative for measurement

strength is a designer's alphabet. Material deformation is closely related to the interplay of interatomic forces between the building elements of a given substance. Technological properties of materials are determined by interatomic interactions. Tested thin-walled components may be made of different materials and with different thickness of the wall Figure 1.

\section{FIRST DRAFT JIG DESIGN ALTERNATIVE FOR MEASUREMENT}

The basic part of the first alternative, Figure 2 , consists of a base with two milled grooves. The first, larger groove serves the purpose of clamping the thin-walled component by means of four screws to secure its position in the $\mathrm{X}, \mathrm{Y}$ and $\mathrm{Z}$ axis direction. The lower part of the base features milled indentation for clamping the jig itself. The second, narrower groove serves the purpose of clamping the thrust plate. A protective washer is inserted between the thrust plate and the clamping screws to protect the thrust plate surface. 12 threaded holes are made into the thrust plate to ensure variable directing of the thrust force onto the thin-walled component.

Advantage:

- low price of the jig,

- fast, simple and solid fixation of the thinwalled component,

- higher stiffness of the thrust plate.

Disadvantage:

- smaller inaccuracies in fixating the material intended for measurement,
- fewer measuring options at different height clearances of thin-walled components,

- greater labor intensity of jig production.

\section{SECOND DRAFT JIG DESIGN ALTERNATIVE FOR MEASUREMENT}

The basic part of the second alternative, Figure 3 , consists of a base with only one milled groove, which serves the purpose of clamping the thin-walled component with four screws to secure its position in the $\mathrm{X}, \mathrm{Y}$ and $\mathrm{Z}$ axis direction. The lower part of the base features milled indentation for clamping the jig itself. The thrust plate clamping is done by clamping screws without a protective washer. 6 threaded holes are made into the thrust plate to ensure variable directing of the thrust force onto the thin-walled component.

Advantage:

- low price of the jig,

- fast, simple and solid fixation of the thinwalled component,

- lower labor intensity of jig production.

Disadvantage:

- smaller inaccuracies in fixating the material intended for measurement,

- fewer measuring options at different height clearances of thin-walled components,

- lower stiffness of the thrust plate.

\section{THIRD DRAFT JIG DESIGN ALTERNATIVE FOR MEASUREMENT}

The basic part of the third alternative, Figure 4 , consists of a base with again only one milled groove, which serves the purpose of clamping

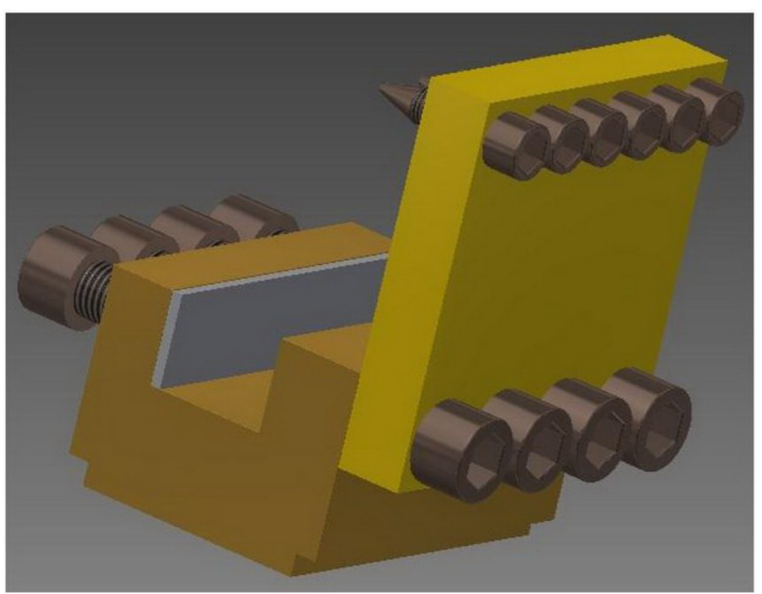

Fig. 3. Second draft jig design alternative for measurement 


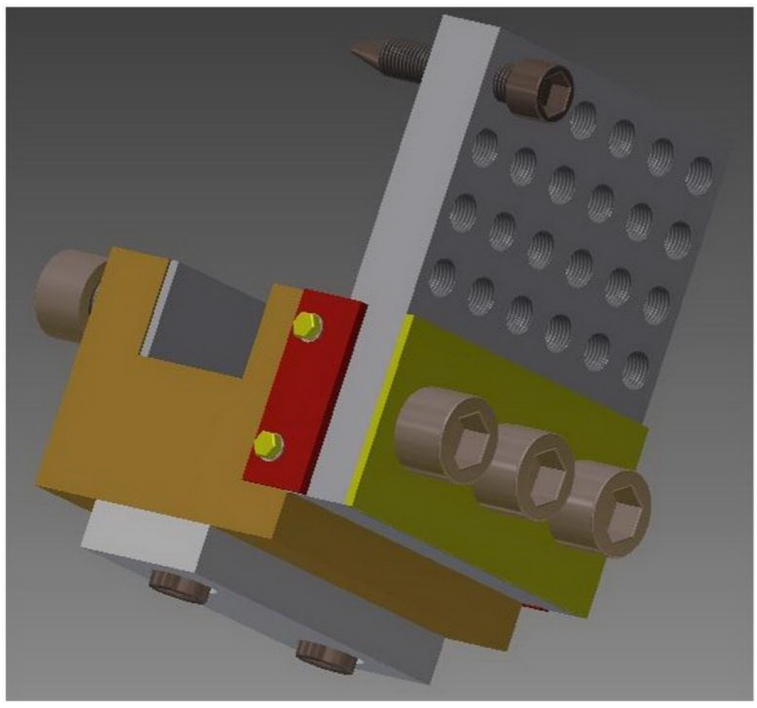

Fig. 4. Third draft jig design alternative for measurement

the thin-walled component with four screws to secure its position in the $\mathrm{X}, \mathrm{Y}$ and $\mathrm{Z}$ axis direction. The lower part of the base does not feature milled indentation. Rather, a jut is fastened there with a screw, for clamping the jig itself. Clamping of the thrust plate is done by the clamping screws with a protective washer. 24 threaded holes are made into the thrust plate to ensure variable directing of the thrust force onto the thin-walled component.

Advantage:

- greater accuracy of material fixation intended for measurement

- fast, simple and solid fixation of the thinwalled component

- greater thrust plate stiffness

- more measuring options at different clearances of thin-walled components

Disadvantage:

- higher jig price

- greater labor intensity of jig production

\section{SELECTING AN ALTERNATIVE}

Prior to selecting the jig option for subsequent production, all options were subjected to
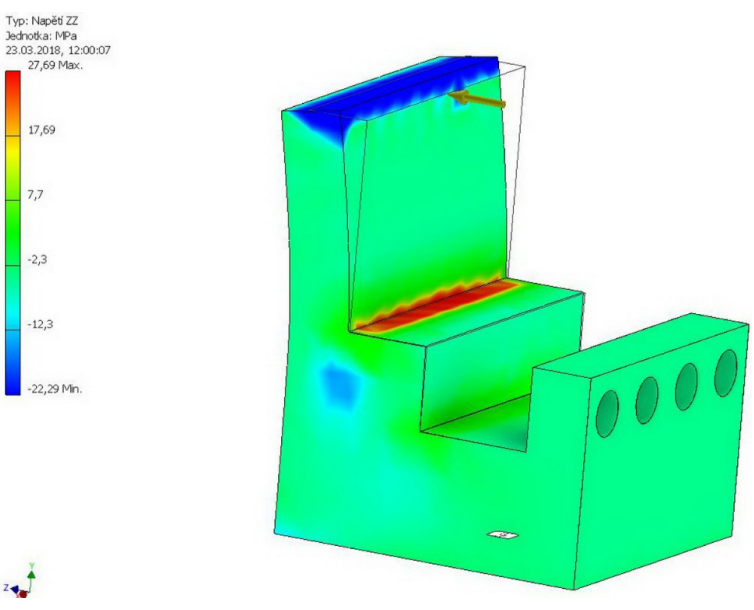

Fig. 5. Stress in ZZ for burdening force $8000 \mathrm{~N}$
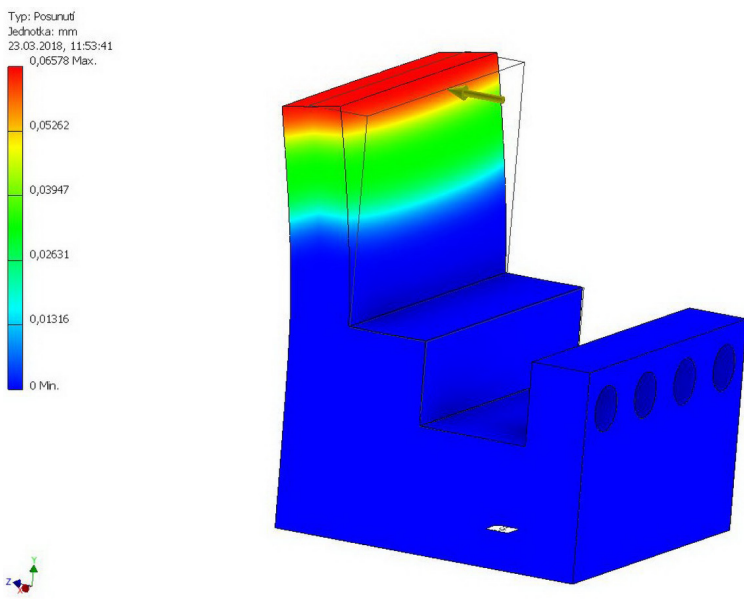

Fig. 6. Displacement in axis $\mathrm{Z}$ for burdening force $8000 \mathrm{~N}$

stress analyses. ZZ stress of $8000 \mathrm{~N}$ thrust force Figure 5 and displacement Figure 6.

Option 3 was selected for further processing, namely the clamping of the thin-walled component into the jig with a movable thrust plate. This involves a more detailed jig processing as this jig ensures the stability of clamping and the clamping speed of the thin-walled component in the jig. The main factors are speed, accuracy, security of clamping and more options of directing the thrust force onto the thrust

Table 1. Comparison stress and displacement of three alternatives

\begin{tabular}{|c|c|c|c|c|c|c|c|c|c|}
\hline \multirow{2}{*}{$\begin{array}{l}\text { Burdening force } \\
{[8000 \mathrm{~N}]}\end{array}$} & \multicolumn{6}{|c|}{ Stress max [MPa] } & \multirow{2}{*}{$\begin{array}{c}\text { Displacement max [mm] } \\
X\end{array}$} & \multirow[b]{2}{*}{$Y$} & \multirow[b]{2}{*}{ Z } \\
\hline & $X X$ & $X Y$ & $X Z$ & YY & YZ & $\mathrm{ZZ}$ & & & \\
\hline Alternative $\mathrm{n} .1$ & 30,17 & 4,87 & 5,58 & 67,93 & 22,79 & 34,51 & 0,00352 & 0,0245 & 0,0867 \\
\hline Alternative $\mathrm{n} .2$ & 24,74 & 4,06 & 4,87 & 52,85 & 19,69 & 31,27 & 0,00269 & 0,0184 & 0,0765 \\
\hline Alternative n.3 & 19,18 & 3,23 & 3,89 & 46,98 & 14,23 & 27,69 & 0,00151 & 0,0129 & 0,065 \\
\hline
\end{tabular}




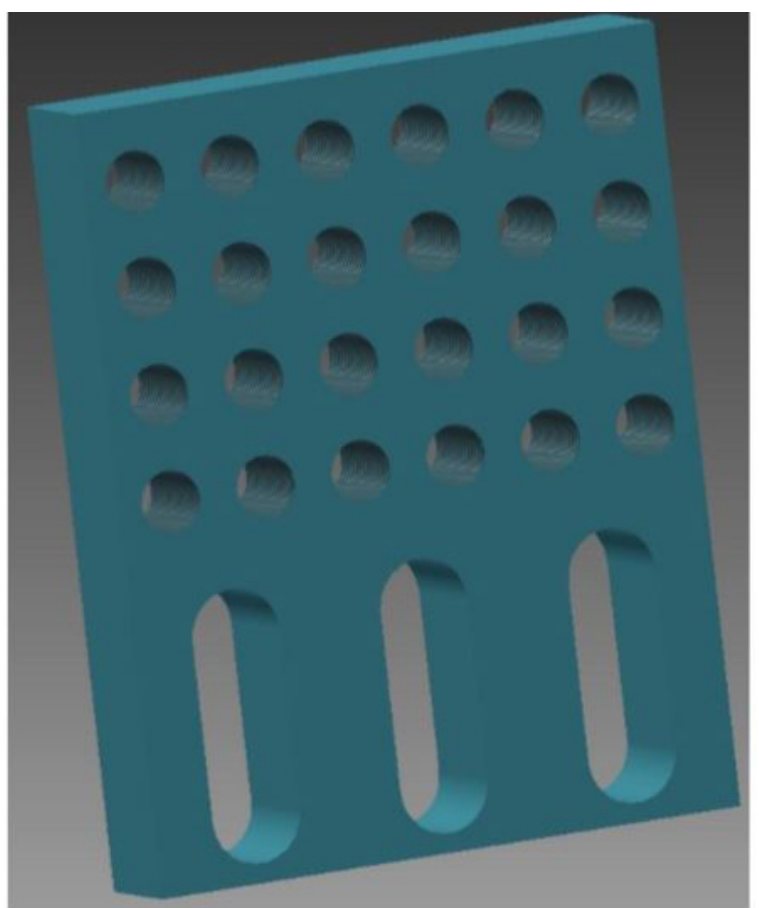

Fig. 7. Pressure plate with grooves and tapping holes

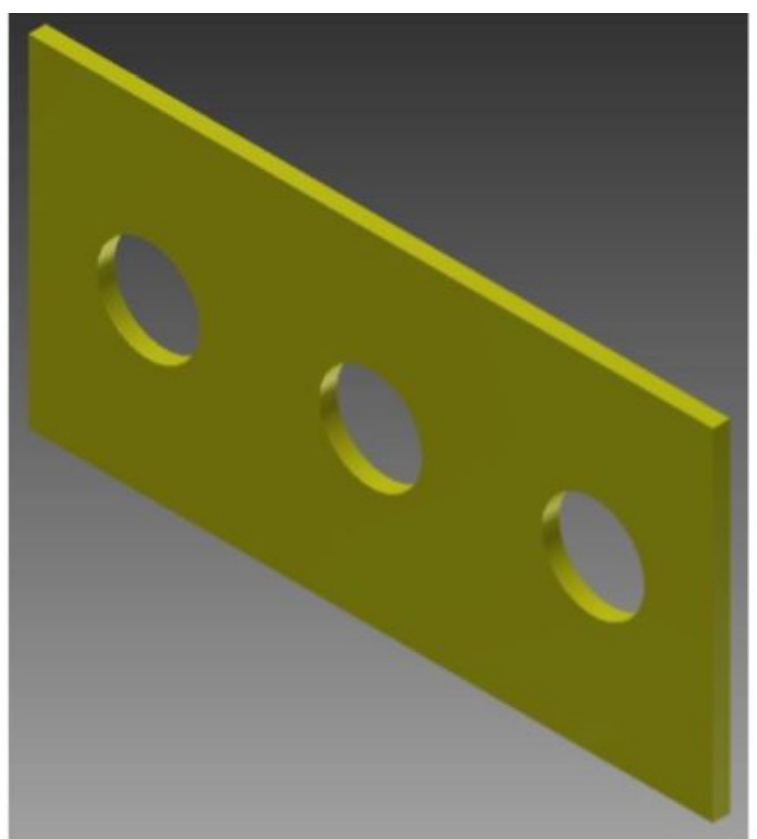

Fig. 8. Special plate for pressure plate

plate Figure 7 and taking different degrees of stress and deformation into account Table 1.

To increase the stability of the thrust plate during the measurement, a special washer under the fastening screws was used Figure 8.

The jig base plate's clamping into the clamping device is ensured by the fastening plate Figure 9 .

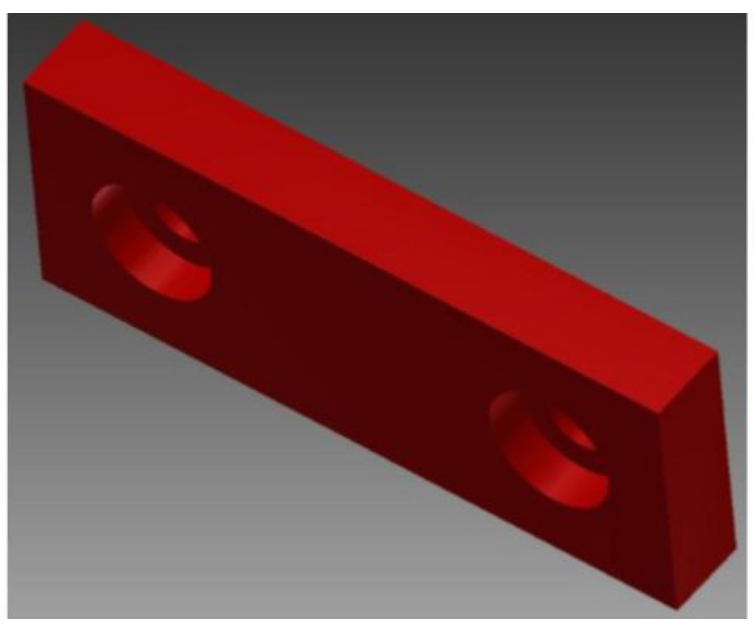

Fig. 9. Fastening plate of baseplate

The thin-walled robotic and conveyor component deformation measurement jig Figure 10 was made of C45 steel at the Pinnacle VMC 650S $\mathrm{CNC}$ machining center and the FNG $40 \mathrm{CNC}$ milling machine. The saw blades used were made of LOGU030310ER-GM sintered carbide.

\section{CONCLUSIONS}

When designing a control jig, one needs to consider the manner of part installment. It is necessary to allow a damage-free assembly and dismantling of a part inside the jig. From the quality point of view, each part of the control jig has to be labeled and identified. Such labeling cannot be applied to the functional surface. In addition

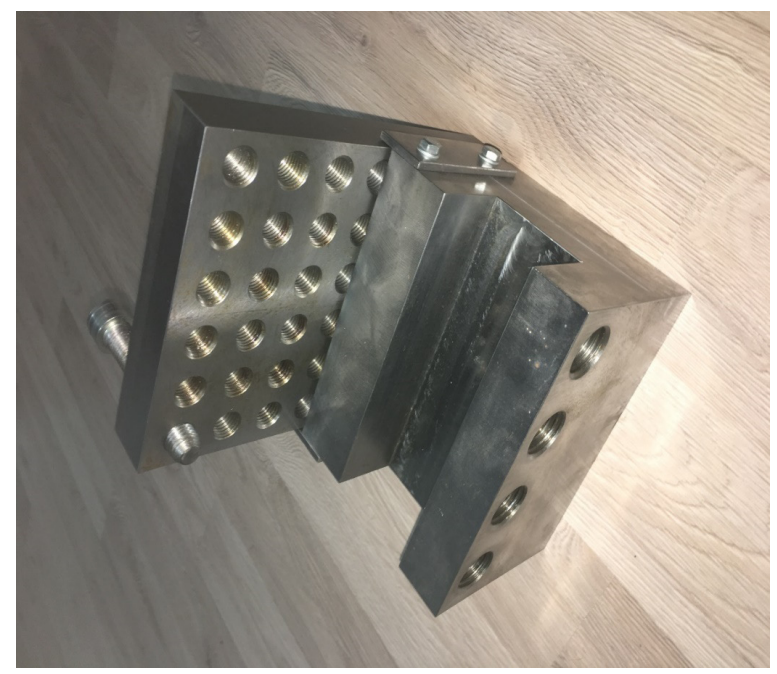

Fig. 10. Manufactured preparation for measurement of deformation thin - walled robotic or conveyor components 
to already mentioned parts, the control jig must also contain the parts necessary for the jig handling. For smaller sized control jigs, those are usually holes drilled into the control jig structure. For handling larger sized control jigs, hinges are available on the structure. Current trends in the automotive industry emphasize constant cost cutting, which also translates into the need to reduce the jig prices. Despite the fact that the price of control jigs often far exceeds the cost of controlled parts, due to their relatively multiple number of use, the price is relatively low. Cost reduction in jig designing is achieved in particular by effective use of individual jig parts, thus reducing the number of parts from which the product is composed and by choosing the right material (material with the desired properties at an affordable price). Of course, price reductions must not affect the functionality, reliability and durability of the jig. Based on the results of stress and deformation analyses, the third alternative was chosen for subsequent production, Figure 10, when a maximum stress of $27.69 \mathrm{MPa}$ and a maximum deformation of $0.065 \mathrm{~mm}$ in the $\mathrm{Z}$ axis direction occurred under $8000 \mathrm{~N}$.

\section{Acknowledgements}

This work is a part of research project VEGA 1/0045/18, VEGA 1/0492/16, KEGA,004TUKE-4/2017.

\section{REFERENCES}

1. Liptai, P., et al.: Check measurements of magnetic flux density: Equipment design and the determination of the confidence interval for EFA 300 measuring devices, Meas. J. Int. Meas. Confed. 111 (2017) 51-59.

2. Dębski, H., et al.: Numerical and experimental analysis of the progressive gear body with the use of finite-element method Badania numeryczne i doświadczalne konstrukcji chwytacza progresywnego z wykorzystaniem metody elementów skończonych *, 17 (2015) 544-550.

3. Molnar, V., et al.: Influence of tension force asymmetry on distribution of contact forces among the conveyor belt and idler rolls in pipe conveyor during transport of particulate solids, Measurement. 63 (2015) 120-127.

4. Lehocka, D.: Comparison of the influence of acoustically enhanced pulsating water jet on selected surface integrity characteristics of CW004A copper and CW614N brass, Measurement. 110 (2017) 230-238.
5. Honus, S., et al.: The effect of the number of conveyor belt carrying idlers on the failure of an impact place: A failure analysis, A Fail. Anal. (2017).

6. Mantic, M.:, et al.: Influence of selected digitization methods on final accuracy of 3D model, (2016) 475-480.

7. Kral, J.,et al.: Creation of 3D parametric surfaces in CAD systems., Acta Mech. Slovaca 2008. (n.d.) 223-228.

8. Tor-Świątek, A., et al.: Quantitative Assessment of the Microscopic Structure of Extruded and Injected Low-Density Polyethylene Modified with Microspheres by Image Analysis, Cell. Polym. 35 (2016) 67-84.

9. Fedorko, G., et al.: Failure analysis of irreversible changes in the construction of rubber- textile conveyor belt damaged by sharp-edge material impact, Eng. Fail. Anal. 39 (2014) 135- 148.

10. Fedorko, G., et al.: Failure analysis of irreversible changes in the construction of the damaged rubber hoses, Eng. Fail. Anal. 58 (2015) 31-43.

11. Molnár, V., et al.: Monitoring of dependences and ratios of normal contact forces on hexagonal idler housings of the pipe conveyor, Measurement. 64 (2015) 168-176.

12. Fedorko, G., et al.: Transportation of ore by belt conveyors with an application of conveyor impact plates, Metal. Int. 18 (2013) 226-228.

13. Baron, P., et al.: Research and application of methods of technical diagnostics for the verification of the design node, Measurement. 94 (2016) 245-253.

14. Aslani, F., et al.: Behaviour and design of hollow and concrete-filled spiral welded steel tube columns subjected to axial compression, J. Constr. Steel Res. 128 (2016) 261-288.

15. Fang, G.W.R. Gao, X.G. Zhang, Finite Element Simulation and Experiment Verification of Rolling Forming for the Truck Wheel Rim, Int. J. Precis. Eng. Manuf. 16 (2015) 1509-1515.

16. Jonsson, B., et al.: Weight optimization and fatigue design of a welded bogie beam structure in a construction equipment, Eng. Fail. Anal. 19 (2012) 63-76.

17. Troive, L., et al.: Springback compensation for a vehicle's steel body panel, Int. J. Comput. Integr. Manuf. 31 (2017) 152-163.

18. Murčinková, Z., et al.: Research and analysis of stress distribution in multilayers of coated tools, Int. J. Mater. Res. 108 (2017) 495-506.

19. Futáš, P., et al.: The GIST of thermal stresses of cast iron castings, Manuf. Technol. 13 (2012) 173-179.

20. J. Strohmandl, Use of simulation to reduction of faulty products, UPB Sci. Bull. Ser. D Mech. Eng. 76 (2014) 223-230. 